Qué hacemos con la Universidad? Los grados que o
Felipe De Ferrari En nuestra profesión, muchos de los arquitectos que admiramos o de
los cuales aprendemos adquieren tintes de personaje literario. No cabe explicitar el proceso, pero sí cabe declarar que Guillermo Jullian es uno de esos casos.

El jueves 12 de junio de 2008 la Escuela de Arquitectura de la Pontificia Universidad
Católica de Chile reunió en una celebración a profesoress, arquitectos y estudiantes para recordar a Guillermo Jullian. Con un montaje realiazado por Alex Morenon y yunto
con las intervenciones de José Rosas, Rodrigo Pérz de Arce, Ann Pendleton y Enesto Rodríguez, se presentatron videos realizados por José Luis Caeate, Sebastian Bianchi i

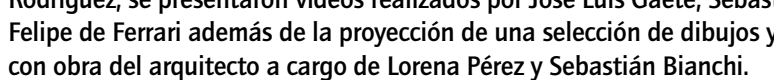

"TTengo que hacer obras! Hacer obras, eso es arquitectura!"

Una de las personas que probablemente lo conocía mejor -y a través que parecia un alumno más. Habra que agregar que parecia uno de esos

\section{De ida y vuelta}

Mito para sus familiares y cercanos, mito-lógico para los de nuestra generación: Guillermo Jullian -de algún modo uno de los nuestros, aunque ex
alumno de la Escuela de la Universidad Católica de Valparáiso- ya era parte del impresionante laboratorio de arquitectura del s. xx que fue per atelier de Le Corbusier. Ingresaba alli joven e inmensamente convenconvento jesuita; inicialmente a solas con Le Corbusier y luego acompa hado por un puñado de Colaboradores, siempre en un anbiente intino.

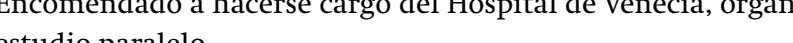
Cerrado el atelier,

Intentaron concluir los proyectos pendientes y avivar la la llama de la arquitectura moderna, de la cual se sentían custodios. Se nutrían de su emorable experiencia laboral, entonces tan lejana a la academia. E

Venecia, Lyon, Valencia, Rabat, Argel, Madagascar, Como Brasilia, Wars lington, Lexington, Ithaca, Roma, Santiago, Zapallar; geografias dis persas, destinos de proyecto, mientras trasladaba su taller de Venecia on: luego a Boston y Santiago. Recientemente estudiaba un ascensor para Valparaíso, ciudad que era su acertijo favorito. Enseñó en Kentucky, Rice, Filadelfia, Cornell, Cooper Union y otras destinaciones siendo en estos últimos años profesor de las universidades
Diego Portales, Andrés Bello y Católica de Chile. Expuso su obra amplia-

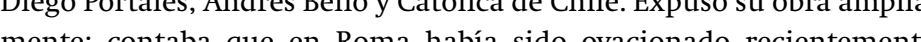
como un boxeador triunfante. Nuestra escuela tuvo el privilegio de recibir su archivo documental, testimonio de su trayectoria, transformado as en razón de estudio.

Decía Picasso lo que se podría decir de Jullian: "toda mi vida traté de dibuCornell. El candor -no la ingenuidad- fue quizás su rasgo profesional académico saliente. El arte de la vida fundamentaba sus proyectos. color brilla en toda su obra.

gegramente le hubiera gustado saber que murió un Viernes Santo y viaje simétrico que lo llevó tempranamente a París, cuyo destino debía ser cerrar en su origen el gran itinerario de su vic. cido. Siete años intensos lo ocuparon en la famosa galería del antiguo extamo y depuradas que exhibiría unescos contrastaba con las pinturas plemente se dieron de ese modo. No así el lugar fijado en un phindel cual muchos lo conocimos-decía hoy acerca de Jullian: "un profeser an por enfrentarse a los convencio

Lo metemos al computer y listo"

Jullian el academicismo duro le parećáa una trinchera extraña y dis A que se contrapone a lo íntimo y cercano que es el trabajo como rquitecto. Parecia tener la bayoneta -o el bastón- lista para una estocada. Hábil al momento de establecer una discusión, en último caso, su .

"Mira... why not"

Lo motivaba el ingenio, la picardía, lo evidente, la intuición y la deriva "Vamos a reaccionar ante el espacio y los actos conjugados"

Le molestaba la torpeza, la neutralidad, el desgano, el amaneramiento to lo lo que atentara contra el acto poético de hacer arquitectura.

"Mi mamá siempre me decía: Lo que tienes que hacer, hazlo"

Guillermo construyó su discurso y obra con cimientos dispares. Estableor relaciones licitas e lilicitas (no se trata de eso el acto creativo?). Se dejó seducir y encantar por esas asociaciones propias. Algunas veces las pere es que a perder- sino haberlo jugado completo con la misma intensidad

(...) Un libro de recortes y anotaciones. No queria en verdad, escribiri una noveln The Isa hasta que

Como los grandes, partió en su mejor momento. Al tope de la ola (al menos eso nos hizo creer), haciendo proyectos en la ciudad que lo formó, preparando su propia retrospectiva, proponiendo talleres en
islas imaginarias. Probablemente -si el tiempo no lo hubiera alcanzadeel próximo taller a su cargo habría contemplado dar la vuelta al mundo en 80 días. 